\title{
关于市政景观工程建设的探讨
}

郑凯元

新疆天宇建设工程有限责任公司

DOI:10.18686/bd.v2i3.1271

[摘 要] 随着中国经济的快速发展,市政工程越来越受到重视。城市建设质量与城市经济发展有关。在现代概念中,除了实 用性和经济性之外,市政工程的美学也不容忽视。市政工程的景观设计决定了市政工程的美。老城区的改造和新城区的建设 都为市政工程的景观设计带来了难得的机遇。在提高市政工程实用性的基础上,抓住这些机遇,科学规划市政工程,提高城市 形象,增加城市美观。另外,在中华民族五千年的传统历史中,不同的城市都有其特有的历史文化遗产。这些历史的细节和文 化遗产可以体现在旧城区的城市重建和新城区的建设中。突出显示增加城市的韵味。本文就市政景观工程建设存在的问题, 探讨了科学的实践建设策略,从观念的转变,打造生态城市景观,增加设计的艺术性等方面进行了详细的分析。

[关键词] 市政景观; 工程;建设

市政景观是在首先满足市政设施使用功能前提下,将 各种功能元素进行有序治理和美化的行为, 它是在市政工 程特定的空间范围内,围绕着道路、桥梁等市政工程主体,创
造一个安全、艺术、和谐的怡人空间环境, 它既不是改造现 有的,也不是创造新生的。道路、桥梁及附属设施等工程主 体的整体形式、空间布局、单体样式、位置、大小、这些都是
表 1 应用八轮连续平整度仪器进行检测的结果

\begin{tabular}{|c|c|c|c|c|c|}
\hline 桩号 & 层次 & 要求标准值 & 总点数 & 合格点数 & 合格率 $(\%)$ \\
\hline$Z K 10+120 Y-Z K 12+251$ & 上面层 & 不超过 0.8 & 34 & 27 & $\approx 79$ \\
\hline$Y K 11+130-Y K 11+230$ & 上面层 & 不超过 0.8 & 57 & 55 & $\approx 95$ \\
\hline
\end{tabular}

2.2 在对路面抗滑性能进行检测时

路面抗滑能力是路面安全性能要求中的重要指标, 其 中包括路面摩擦力和路面抵抗车辆滑动力两项能力, 能够 反映出路面与车辆轮胎之间的摩擦力大小, 摩擦力能够为 车辆的运行做出安全保障。因此,在现阶段进行路面抗滑性 能检测主要使用的是摆式仪器, 通过仪器测试出的摆值进 行抗滑能力定级。文章中论述的抗滑性能检测主要是在工 程规范要求的比例下进行的检验测试, 而且测试结果都合 格,具体的检测数据如表 2 所示。

表 2 摆式仪器检测路面抗滑性能数据表

\begin{tabular}{|c|c|c|c|c|c|}
\hline 桩号 & 层次 & 要求数值 & 总点数 & 合格点数 & 合格率 $(\%)$ \\
\hline $\mathrm{Y} 10+120-Y K 11+060$ & 上面层 & 至少超过 45 & 9 & 9 & 100 \\
\hline$Z K 11+230-Z K 11+760$ & 上面层 & 至少超过 45 & 6 & 6 & 100 \\
\hline
\end{tabular}

\section{3 在对路面渗水能力进行检测时}

进行沥青混凝土路面渗水能力检测主要是对路面在碾 压成型后或碾压现场进行沥青混合料取芯时各试件的渗水 性能检测以及得出准确的渗水系数, 并且验证施工中混合 料在配合比设计上是否合理。沥青混凝土路面施工有一个 基础性特点, 就是施工中应用的主要原材料,也就是沥青和 混凝土,其二者本身就具备防水性能,能够阻挡正常降雨情 况下雨水的渗透。而对沥青混凝土路面渗水能力的检测也 是在进行沥青混凝土料级配比评定时参考的间接指标,因 在施工完毕后, 沥青混凝土路面就会自动在面层结构上生 成一层不透水层,但其上面层是具备透水功能的,所以在降
水天气,雨水渗人到路面的上面层后会逐渐下渗,使路面表 面无法形成水膜, 这在一定程度上提高了路面的抗滑性能, 降低了车辆在行驶过程中与路面摩擦发出的噪音。其检测 中的渗水系数主要是指在标准规定的水压状态下, 在单位 路面面积上, 单位分钟内水通过路面表面渗人路面下层结 构中的水量,其中具体的检测数据如表 3 所示。

表 3 单位路面面积、单位时间内,路面渗水能力检测数据表

\begin{tabular}{|c|c|c|c|c|c|}
\hline 桩号 & 层次 & 要求数值 & 总点数 & 合格点数 & 合格率 $(\%)$ \\
\hline$Z K 11+440-Z K 12+890$ & 上面层 & 不超过 300 & 15 & 15 & 100 \\
\hline$Z K 11+440-Z K 12+890$ & 上面层 & 不超过 300 & 10 & 9 & 90 \\
\hline$Z K 11+050-Z K 12+990$ & 中面层 & 不超过 300 & 20 & 18 & 90 \\
\hline$Z K 11+440-Z K 12+890$ & 中面层 & 不超过 300 & 3 & 3 & 100 \\
\hline AK0+198-ZK12+890 & 中面层 & 不超过 300 & 5 & 5 & 100 \\
\hline$Z K 11+440-Z K 12+890$ & 中面层 & 不超过 300 & 12 & 12 & 100 \\
\hline
\end{tabular}

\section{3 结束语}

综上所述, 沥青混凝土在进行路面检测的监理工作中, 工作人员要给予高度重视, 明确的意识到这项工作是关系 到路面施工质量、使用舒适度的关键步骤。而且要将这项工 作贯穿到施工始末,从施工准备阶段的材料检测出发,直至 施工完毕后各项性能检测,都要有监理工作的加人; 而且监 理单位要用科学的方式、手段进行质量检测, 并呈现出客 观、真实的检测报告,用于施工指导上,从而为道路的安全使 用做出保障。

\section{参考文献:}

[1] 陈非. 基于沥青混凝土路面检测的监理工作分析 [J].交通世界,2017,(Z1):75-76.

[2]连晓琼.沥青混凝土路面检测新技术的应用 [J].住 宅与房地产,2018,(08):164-165.

[3] 陈旭. 沥青混凝土路面检测方法及影响因素研究 [J].建材与装饰,2018,(10):311-312. 
市政景观所需要考虑的。景观工程能够显著提升工程本身 乃至周边环境的价值一一这已经为中外无数案例所证明。 对于市政工程而言,因其为社会共享的资源, 具有显著的社 会公益性特征,因此,其景观工程的作用和意义更加突出。有 鉴于此, 在现今的国内市政工程建设中, 景观工程得到了普 遍重视。

\section{1 景观工程建设存在的问题}

市政景观工程建设, 由前期设计方案阶段直至完工, 需 要经历较长的时间。同时设计方案并非全面固定,随着施工 进程的开展, 会呈现出较多未可知问题与不确定状况, 令设 计人员改变初衷。而当前相关城市管理法规、控制手段,仅 对市政工程功能明确了要求, 没有涉及到具体要素的实施 标准。为此应做好城市规划的科学编制与设计。同时,基于 专业分工的逐步细化,协同合作更为重要,其实施基础在于 各专业的良好沟通与技能知识的相互了解渗透。而当前,较 多景观设计人员知之甚少, 无法由工程特征人手展开规划, 促进市政景观工程的外在、内涵的全面统一工程施工现场 还体现出保护管线不良,在欠缺资料的基础上,没有做好全 面勘察,探坑施工,无法良好落实保护策略、各工种专业、部 门配合不良等弊端问题。再者,市政景观工程的建设还体现 出人性化功能不足的状况, 虽然较多区域设置了盲道、零障 碍道路,然而现实状况却是, 人性化的规划建设逐步被人行 道、井盖、停车位等取代,或被不良商贩挤占,造成了资源效 益的不良浪费,并违背了人性化设计规划初衷。市政工程实 践施工阶段中,必然涉及到施工队之间、各工种、部门之间 的协调配合，倘若欠缺经验丰富、协调控制人员的良好管控， 则即便设计再精良,也会影响到市政工程建设效果。市政景 观工程项目包含较多专业, 例如道路、照明系统、排水工程、 电力、水利、生态绿化等。因此应全面做好区域布设规划,积 极开展跨部门协同合作与跨行业交流,优选调控人员, 降低 重复交叉冗余工作, 提升市政景观工程建设效率与城市规 划水平。

\section{2 解决市政景观工程建设的策略}

2.1 传承保护历史遗产, 打造生态城市景观

我国上下五千年的文明历史, 为后人留下了较多珍贵 历史遗产。因此在市政景观建设阶段中,我们应基于历史遗 产特色,全面保护, 合理运用于城市规划打造中,凸显历史文 化内涵。在改造建设阶段中,对符合我国人文精神的庭院景 观应全面保留,进而体现地域化的人文色彩,并给人以良好 的审美视觉享受。倘若在交通要塞位置、城市核心地带, 单 纯的保留一颗孤树,则会破坏整体的市政景观效果,因此这 样的保留意义不大。我们应依据周围景观特点、辩证的做好 历史遗产的传承保留与科学设计应用。同时应树立生态理 念,全面优化环保建设, 开展市政绿化工程规划设计,创造出 绿色、环保、生态、艺术美观的市政景观工程。

2.2 转变观念是当务之急

改革开放后特别是近十年,中国城市高速发展,而就城
市发展而言,人们的观念和认识已远远落后于变化和发展。 长期以来, 我国城市建设特别是市政工程遵循着实用、经 济、在可能条件下讲究美观的原则,这个原则是在建国初期, 根据我国当时的实际情况, 快速改善城市面貌的思路下制 定的。然而城市在发展, 社会在进步, 人们对城市生活的要 求, 不仅在于空间使用功能的满足以及工程本身的美观, 更 主要是在于城市整体环境的质量。当代城市空间形态和过 去相比较,正朝系统化、立体化演进。传统的观念缺乏对三 维空间及人的生理、心理、社会精神要求更深层次的考虑。 根据在可能条件下讲究美观这一原则不可能创造高质量的 城市形体环境和城市生活环境。为了适应现代城市的发展 和建设的需要, 现代城市设计已在我国兴起, 其目的就是为 了提高城市环境的质量, 从而改进人的生活质量, 给人带来 可能的最大便利与舒适,给人以美的享受。现代城市设计与 城市规划、建筑学、景观建筑学、市政工程学等密切关联,并 与社会学、经济学、生态学、环境学、法学和城市管理学等学 科有关, 城市设计是这些学科的相关内容在城市物质、社 会、环境结合点上的综合体现。市政工程是城市设计的重要 组成部分,其功能及空间和城市设计密不可分, 要提高城市 环境质量, 就必须在市政工程设计中融人城市设计的理念, 改变过去那种只注重自身功能或形象而漠视城市整体的观 念,从城市整体出发,将市政工程作为城市空间体系中的一 个组成部分而加以处理。注重对三维及四维空间的设计和 对人的生理、心理、社会和精神要求的考虑,在内容和形式 上和城市有机结合起来。时代要求我们用现代城市设计的 理念来替代传统的观念。

\section{3 细化分工}

《中华人民共和国城市规划法》第十九条规定: 城市总 体规划应当包括: 城市的性质、发展目标和发展规模,城市 主要建设标准和定额指标, 城市建设用地布局、功能分区和 各项建设的总体部署,城市综合交通体系和河湖、绿地系统, 各项专业规划,近期建设规划。

在《中华人民共和国城市规划法》明确规定了在市政工 程建设中应当注重各项专业规划, 也就是说应当在市政工 程建设中细化分工, 不能将景观设计与传统的市政工程中 的实用性和经济性混淆在一起。应该在市政工程中分工明 确, 将各种分工都重视起来, 尤其是关系到城市品味和城市 影响的景观设计方面。

\section{4 增加艺术性}

在市政工程建设过程中市政工程建设的艺术性往往是 容易被市政工程管理部门忽略的一部分。市政工程的艺术 性不只是单纯意义上市政工程的美观性, 还包括城市建设 中可以包含的城市文化底蕴和历史底蕴。中华民族有五千 年悠久的历史,赋予了每个城市不同的历史底蕴, 在悠久的 历史中每个城市又有其与其他城市不同的文化, 充分挖掘 和展示这些历史和文化必将使城市在竞争中脱颖而出。

在市政工程的景观设计过程中艺术性也必不可少,增 


\section{基于 BIM 的工程造价精细化管理研究}

宗如娜 房亚宁

陕西省采购招标有限责任公司

DOI:10.18686/bd.v2i3.1308

[摘 要] 在社会经济迅速发展的背景下, 工程项目不断增多。在市场环境下,建筑企业越发注重工程经济效益的增长, 其主 要原因在于经济效益是建筑企业赖以生存基础条件。因此, 在工程建设过程中,建筑企业越发注重工程造价的精细化管理, BIM 技术作为一项现代化技术,在工程造价精细化管理当中的应用,能够有效提升工程造价精细化管理质量,为提高工程经 济效益奠定夯实的基础。本文主要是就工程造价精细化管理问题进行了更深层次的剖析,并探讨了基于 BIM 的工程造价精 细化管理。

[关键词] BIM; 工程造价; 精细化管理

所谓 BIM 的工程造价精细化管理, 主要是借助现代先 进的数字化技术,利用 BIM 工程造价精细化管理,以此有效 提升工程造价质量, 为建筑企业经济效益的提升奠定夯实 的基础。BIM 工程造价管理,主要是借助数字信息技术,真实 模拟工程建筑项目的具体情况,具体包括建筑三维信息、工 程造价以及工程项目质量等,通过汇总建筑全部信息,实现 工程造价管理的信息化管理, 以此有效提升工程造价精细 化管理质量。

\section{BIM 工程造价精细化管理概念概述}

所谓“BIM 工程造价精细化管理”,主要是在工程项目 建设过程中, 将工程造价管理融人到每一环节当中, 促使工 程每一环节的人力资源、技术资源等能够得到合理配置, 避 免工程建设过程中出现了人力、物力以及财力等资源的浪 费, 从而能够在保障工程质量的基础上,提升工程经济效益。

工程造价精细化管理涉及到工程建设方方面面, 传统 的工程造价管理侧重在施工过程中, 忽视了前期设计以及 后期验收环节的工程造价管理工作, 同时传统的工程造价 管理模式主要以粗放型方式为主, 造成施工过程中存在严 重的资源浪费,种种因素的共同作用,造成工程造价管理质 量与效率低下, 不利于工程经济效益的提升。然而精细化管 理, 主要是在确定工程造价之后, 借助监督管理等手段, 严控 造价, 在工程建设的每一环节,均进行必要的造价管理。简单 来说,在工程前期,需要对工程造价加以预算, 并确定最高限 额; 在工程决策阶段, 需要对项目投资估算进行控制, 具体体
现在设计估算。为了确保设计估算的合理性, 就需要在设计 阶段,注重设计的优化。在工程招投标阶段,应该对工程合同 的签定引起高度重视, 结合工程前期方案与具体施工方案, 做好预付款与进度款等工作,避免工程款随意发放。

\section{2 工程造价精细化管理中亟需解决的一系列问题分析}

随着工程项目的不断增多,市场环境变化, 建筑企业越 发注重工程造价精细化管理, 均希望以此促进工程经济效 益的提升。然而在工程造价精细化管理工作实施过程中, 还 具有众多问题亟需解决, 造成工程造价精细化管理质量与 效率低下。

2.1 预算准确性有待提高。工程造价管理过程中,建筑 企业虽十分注重精细化管理工作的落实, 并且取得了一定 成效,但是在实际操作当中, 出现了预算准确性低下这一问 题, 严重影响到工程造价管理水平与质量的提升。影响工程 造价预算准确性的因素众多,例如信息收集不够全面、遗漏 部分工程项目等。除此之外, 在工程造价预算编制过程中, 相 关人员并没有进行现场勘察, 在不熟悉工程具体情况的基 础上,便凭借设计图依据经验进行预算编制, 造成工程项目 信息不全,从而出现了数据资料统计问题,同时预算人员自 身综合素质有待提高等问题,种种因素的共同作用,造成预 算准确性偏低。

2.2 信息分析处理滞后。工程项目造价精细化管理在工 程建设全过程中均有所体现, 数据分析作为造价管理关键 一环节, 直接影响到工程造价管理质量。然而在工程造价落

形象的高品质项目。

参考文献:

[1]钱召龙.试析市政道路园林景观工程管理 [J].智能 城市, 2017,3(02):305.

[2]徐东.市政园林景观的项目施工管理分析 [J]. 现代 园艺,2018,(02):200-201.

[3]赵国平.基于工程管理角度分析市政道路绿化景观 [J].江西建材,2017,(21):185+191. 